\title{
Ameliorative Role of Dietary Supplemented Conjugated Linolenic Acid against Nicotine-Induced Toxicity in Rats
}

\author{
Krishna Chattopadhyay ${ }^{1}$, Moumita Maity², Satyam Banerjee ${ }^{2}$ and Brajadulal Chattopadhyay ${ }^{2 *}$
}

${ }^{1}$ Department of Chemical Technology, University of Calcutta, 92 A.P.C. Road, Kolkata 700009, India

${ }^{2}$ Department of Physics, Jadavpur University, 188 Raja S.C. Mallik Road, Kolkata 700032, India

\begin{abstract}
Increasing consumption of tobacco in different forms harms almost every organs of our body. Nicotine is the culprit for various physiological repercussions arouse due to the uptake of tobacco. As nutritional status alters the actions, potencies and detoxification of toxicants, the present study was undertaken to evaluate the natural antioxidant efficacy of conjugated linolenic acid present in Karalla seed against nicotine-induced toxicity. Experiments were conducted on male albino rats (120-130 g body weight) by injecting nicotine tartarate $(3.5 \mathrm{mg} / \mathrm{kg}$ body wt. /day for 15 days) subcutaneously and thereby simultaneously supplementing conjugated linolenic acid ( 0.5 and $1.0 \%)$ to their diets. Nicotine significantly altered serum and liver lipid profiles, lipid peroxidation and activities of antioxidant enzymes. It caused significant decrease of DNA contents $(P<0.01)$ and DNA damage $(P<0.001)$ of liver tissue. Conjugated linolenic acid has the ability to bind with DNA and protein similar to nicotine and thereby ameliorates nicotine-induced toxicity in rats. Thus intake of Karalla that contains conjugated linolenic in its seeds, in our daily diet can effectively attenuate nicotine-induced cellular and genetic damages.
\end{abstract}

Keywords: Conjugated linolenic acid; DNA damage; Docking; Nicotine; Oxidative stress

Abbreviation: $\alpha$-ESA: $\alpha$-Eleostearic Acid; CAT: Catalase; CLA: Conjugated Linoleic Acid; CLnA: Conjugated Linolenic Acid; GPx: Glutathione Peroxidase; HDL-C: High Density Lipoprotein Cholesterol; LDL-C: Low Density Lipoprotein Cholesterol; LPO: Lipid Peroxidation; MDA: Malonaldehyde; OS: Oxidative Stress; PDB: Protein Data Bank; GSH: Reduced Glutathione; ROS: Reactive Oxygen Species; SD: Standard Deviation; SSB: Single-Strand Breaks; SOD: Superoxide Dismutase; TBARS: Thiobarbituric Acid Reactive Substances; TC: Total Cholesterol; VLDL-C: Very Low Density Lipoprotein Cholesterol; HMG CoA reductase: Hydroxy-methylglutaryl-CoA Reductase; BSA: Bovine Serum Albumin

\section{Introduction}

Increasing uses of tobacco products is an alarming danger for health worldwide [1]. Nicotine the culprit component of tobacco causes oxidative damage in the tissues and nucleic acids leading to several diseases. Free radical-induced oxidative damage has been suggested to play a major role in the pathogenesis of smoke-related disorders [2]. During the smoking of cigarette and/or chewing of tobacco, nicotine is at first being converted into highly mutagenic nitrosamine and later metabolized into cotinine [3]. Experiments have shown that chronic administration of nicotine causes increased lipid peroxidation products in serum and various tissues of rats, which is also dose dependent [4]. The increase of lipid peroxidative products is associated with decreased activity of endogenous antioxidants, catalase and superoxide dismutase [5]. It is also established that metabolism of nicotine produces reactive intermediates capable of binding to proteins and DNA which increases the risk of hepatocellular carcinoma [6]. Kleinsasser et al. [7] have shown that nicotine expresses significant direct genotoxic effects in human target cells in vitro. Nicotine also exerts genotoxic effect on hepatic cells [8] and blood cells [9] of rat.

People of all over India and Asia often eat bitter gourds (Momordica charantia). The seed oil of such gourds contains 60\% (wt:wt) $\alpha$-eleostearic acid ( $\alpha$-ESA) and the flesh contains a small amount of $\alpha$-ESA. We are particularly interested in seed oils that contain conjugated linolenic acids (CLnA), which are the only conjugated fatty acids that can be prepared from natural sources in bulk. It has been reported that conjugated linolenic acid has a better anti-tumor effect than conjugated linoleic acid (CLA) [10]. Koba et al. [11] have observed the effect of dietary conjugated linolenic acid on body fat; serum and liver lipid levels with that of conjugated linoleic acid in rats. Theoretically a-eleostearic acid consists of 33\% cis and $66 \%$ trans molecular composition. This conjugated fatty acid is now regarded as natural antioxidant for its oxygen scavenging property [12].

The toxicity of nicotine is the subject of intense scientific scrutiny. The potential damage caused by free radicals is normally minimized by a combination of biological antioxidant systems including enzymatic and non-enzymatic reactions [13]. Nutritional antioxidants that work against oxidative stress related diseases are always desirable and have gained immense interest recently. Naturally occurring therapeutic agents have always added advantage, as it has no negative side effects on our health. Any strategy through natural diet that prevents or slows the progression and severity of nicotine toxicity has a significant health impact. As per knowledge is concerned, hardly reports are found that explore the ameliorative effect of conjugated linolenic acid against nicotine-induced toxicity. This study illustrates that conjugated linolenic acid present in karela seed have potential antioxidative and antigenotoxic role against nicotine-induced toxicity. This naturally

*Corresponding author: Brajadulal Chattopadhyay, Department of Physics, Jadavpur University, 188 Raja S.C. Mallik Road, Kolkata 700032, India, Tel: +919433343917; Fax: +91-33-24138917; E-mail: bdc_physics@yahoo.co.in

Received August 13, 2012; Accepted November 05, 2012; Published Novembe 07, 2012

Citation: Chattopadhyay K, Maity M, Banerjee S, Chattopadhyay B (2012) Ameliorative Role of Dietary Supplemented Conjugated Linolenic Acid against Nicotine-Induced Toxicity in Rats. Pharmaceut Anal Acta 3:182. doi:10.4172/21532435.1000182

Copyright: (c) 2012 Chattopadhyay K, et al. This is an open-access article distributed under the terms of the Creative Commons Attribution License, which permits unrestricted use, distribution, and reproduction in any medium, provided the original author and source are credited. 
found ameliorative agent might have an extra edge over other available nicotinic therapeutic agents on health through daily dietary intake.

\section{Materials \& Methods}

\section{Extraction and quantification of CLnA isomers}

Authentic Karalla seeds, obtained from the local market of Calcutta, India, were crushed into fine particles and oil was extracted from these crushed seeds with solvent petroleum ether. The extracts of the sample were filtered and concentrated by evaporation in vacuum. Then free fatty acid content present in the oil was measured and removed by miscella refining process [14]. The extracted oil containing hexane, known as miscella (hexane/oil, 2:1) was mixed with $10 \% \mathrm{NaOH}$ solution $\left(20 \%\right.$ excess of the theoretical amount required) at $40^{\circ} \mathrm{C}$ for $30 \mathrm{~min}$ to neutralize the free fatty acids. The soap formed was removed by centrifugation and the organic phase was washed with distilled water. De-acidified oil was recovered after removing the solvent under vacuum distillation and drying under vacuum. The refined oil was then bleached with tonsil earth optimum ( $1 \% \mathrm{w} / \mathrm{w})$ obtained from P.T. SudChemic (Jakarta, Indonesia) and activated carbon $(0.2 \% \mathrm{w} / \mathrm{w})$, supplied by E. Merck India Pvt. Ltd. (Bombay, India) at $60^{\circ} \mathrm{C}$ under vacuum for $20 \mathrm{~min}$. After the bleaching operation, the oil was recovered by vacuum filtration and stored at $-20^{\circ} \mathrm{C}$ under nitrogen.

\section{Animal experiment}

The animal experiment was performed by strictly following the rules and regulations of animal ethical committee of the Department of Chemical Technology, University of Calcutta, India. Male albino rats $(\mathrm{N}=40)$ of Wister strain $(120-130 \mathrm{~g}$ body wt.) were housed in individual cages and fed the dietary oils and fresh water ad libitum. After maintaining the animals for 4 weeks, they were divided into four groups (Groups - A, B, C and D), having 10 rats in each. Daily food consumption and weekly body weight gain was recorded. After determination of the effective dose ( $3.5 \mathrm{mg} / \mathrm{kg}$ body wt.), nicotine tartrate (Sigma Chemical Company, St. Louis, MO, USA) dissolved in $0.9 \%$ saline (w/v) was injected subcutaneously at a dose of $3.5 \mathrm{mg} /$ $\mathrm{kg}$ body wt./day for 15 days to the experimental groups (Groups - B, $\mathrm{C}$ and $\mathrm{D})$. Control group (Group-A) was injected normal saline in a similar manner at the same time.

Basal diet was prepared according to the American Institution of Nutrition. The rats were fed experimental diet composed of fat free casein (18\%), fat (experimental fat blends 20\%), starch (55\%), salt mixture (4\%), cellulose $3 \%$ and one multivitamin capsule per $\mathrm{kg}$ of diet. The diet was adequate in all nutrients. Conjugated linolenic acid (sunflower oil: conjugated linolenic acid: 99.5:0.5 w/w and 99.0: 1.0 $\mathrm{w} / \mathrm{w}$ ) was supplemented simultaneously in the experimental group. The dose was selected according to the previous study as described by Dhar et al. [15]

The dietary fat blends were as follows:

Group-A: Sunflower oil (20\% fat) diet (control group without nicotine treatment).

Group-B: Sunflower oil (20\% fat) diet (experimental group treated with nicotine).

Group-C: Sunflower oil (20\% fat): conjugated linolenic acid (99.5:0.5 w/w) (experimental group treated with nicotine).

Group-D: Sunflower oil (20\% fat): conjugated linolenic acid (99.0:1.0 w/w) (experimental group treated with nicotine).
Rats were sacrificed under mild anesthesia, blood was collected and liver tissue was immediately excised, blotted, weighed and stored at deep-freeze temperature $\left(-40^{\circ} \mathrm{C}\right)$ for analysis.

\section{Biochemical analysis}

The lipid components such as total cholesterol (TC) [16], highdensity lipoprotein cholesterol (HDL-C) [17] and triglyceride [18] were estimated in plasma by using standard kits supplied by Ranbaxy Diagnostic Ltd., Mumbai, India. Very high-density lipoprotein cholesterol (VLDL-C) and low-density lipoprotein cholesterol (LDL-C) were calculated from the values of triglyceride, TC and HDL-C by Friedewald and Fredicksons formula [19]. By the assay of thiobarbituric acid reactive substances (TBARS) plasma and liver lipid peroxidation was measured according to the standard method [20]. The amount of malonaldehyde (MDA) was calculated by taking the extinction coefficient of MDA to be $1.56 \times 10^{5} \mathrm{M}^{-1} \mathrm{~cm}^{-1}$. Superoxide dismutase (SOD) [21], catalase (CAT) [22], glutathione peroxidase (GPx) [23] and reduced glutathione (GSH) [24] content of liver were determined in rats of all the four groups. Protein concentration of the tissue was determined by Lowry assay [25]. The entire biochemical assays were repeated twice and data were averaged over 20 results.

\section{DNA damage study}

DNA was isolated from frozen liver tissues by modified the procedure as described by Bandyopadhyaya et al. [26]. About $50 \mathrm{mg}$ of frozen rat liver tissues was thawed in $10 \mathrm{ml}$ of $1 \%$ SDS containing 1 $\mathrm{mM}$ EDTA. The tissue was then homogenized at $4000 \mathrm{~g}$ for $2 \mathrm{~min}$. This cycle was repeated thrice and the homogenate was incubated at $38{ }^{\circ} \mathrm{C}$ for $30 \mathrm{~min}$ with proteinase $\mathrm{K}(500 \mu \mathrm{g} / \mathrm{ml})$. Next $0.5 \mathrm{ml}$ of $1 \mathrm{M}$ Tris-HCl ( $\mathrm{pH}$ 7.4) was added to the homogenate and extracted by centrifugation $\left(4000 \mathrm{~g}\right.$ at $\left.4^{\circ} \mathrm{C}\right)$ successively with one volume each of phenol $(5 \mathrm{~min}), 1: 1$ mixture of phenol/Sevag (chloroform/isoamyl alcohol, 24:1) (3 min), and Sevag (3 min). The phases were separated by centrifugation (14,000 $\mathrm{g}$ at $\left.4^{\circ} \mathrm{C}, 20 \mathrm{~min}\right)$. To the homogenate, 0.1 volume of $5 \mathrm{M} \mathrm{NaCl}$ and one volume of absolute ethanol was added and kept at $-20^{\circ} \mathrm{C}$ for $30 \mathrm{~min}$. DNA thus precipitated was recovered by centrifugation at $14,000 \mathrm{~g}$, $4^{\circ} \mathrm{C}$ for $15 \mathrm{~min}$. DNA precipitate was rinsed carefully in $70 \%$ ethanol twice to remove salt and then dissolved in $0.5 \mathrm{ml} \mathrm{TE}$ ( $\mathrm{pH} 8.0$ ). RNA was removed by incubation at $38^{\circ} \mathrm{C}$ for 30 min with RNAse A $(100 \mu \mathrm{g} / \mathrm{ml})$ in $50 \mathrm{mM}$ Tris- $\mathrm{HCl}(\mathrm{pH}$ 4). After the extraction of this solution with Sevag, DNA was recovered from the aqueous phase as described above, and finally dissolved in $0.2 \mathrm{ml}$ of TE ( $\mathrm{pH} 8$ ), and its concentration as well as purity was estimated spectrophotometrically by measuring absorbencies at 230, 260 and $280 \mathrm{~nm}$. The total DNA content thus obtained was shown in the table as the mean of all observations in respective subgroup along with standard deviation (S.D).

\section{Comet assay}

The procedure for Comet assay was followed as described by Bandyopadhyaya et al. [26]. Preparation of two gel layers only instead of three layers performed the assay. The liver tissues $(50 \mathrm{mg})$ were minced, suspended at $1 \mathrm{ml} / \mathrm{g}$ in chilled homogenizing buffer $(0.075 \mathrm{M} \mathrm{NaCl}$ and $0.024 \mathrm{M}$ EDTA) and gently homogenized at $600 \mathrm{~g}$ for $2 \mathrm{~min}$. To obtain nuclei, the homogenate was centrifuged at $1000 \mathrm{~g}$ for $10 \mathrm{~min}$ at $0{ }^{\circ} \mathrm{C}$, and the precipitate was resuspended in $1 \mathrm{ml}$ chilled homogenizing buffer. About $100 \mu \mathrm{L}$ of $2 \%$ regular melting point agarose (Genei, India) was quickly layered on a pre-cooled fully frosted slide and covered with a cover slip and allowed to solidify. The nuclear preparation was mixed 1:1 (v/v) with $2 \%$ low melting point agarose (Genei, India). The cover slip was removed carefully and a second layer of $100 \mu \mathrm{L}$ of the mixture 
Citation: Chattopadhyay K, Maity M, Banerjee S, Chattopadhyay B (2012) Ameliorative Role of Dietary Supplemented Conjugated Linolenic Acid against Nicotine-Induced Toxicity in Rats. Pharmaceut Anal Acta 3:182. doi:10.4172/2153-2435.1000182

was pipette out on the slide, covered with the cover slip again and allowed to gel at $4^{\circ} \mathrm{C}$ for $15 \mathrm{~min}$. The slide (without cover slip) was immerged in a chilled lysing solution $(2.5 \mathrm{M} \mathrm{NaCl}, 100 \mathrm{mM}$ EDTA, 10 $\mathrm{mM}$ Tris- $\mathrm{HCl}, 1 \%$ Sarkosyl, $10 \%$ DMSO and $1 \%$ Triton X-100, at $\mathrm{pH}$ 10) and kept at $4^{\circ} \mathrm{C}$ for $2 \mathrm{~h}$. The slides were then placed on a horizontal gel electrophoresis platform and covered with chilled alkaline solution made up of $300 \mathrm{mM} \mathrm{NaOH}$ and $1 \mathrm{~mm}$ EDTA ( $\mathrm{pH}$ 12.5). The slides were left in the solution in dark for $15 \mathrm{~min}$ and then electrophoresed at $4^{\circ} \mathrm{C}$ in the dark for $15 \mathrm{~min}$ at $1 \mathrm{~V} / \mathrm{cm}$ and approximately $250 \mathrm{~mA}$. The slides were gently rinsed in neutralization buffer $(0.4 \mathrm{M}$ Tris- $\mathrm{HCl}, \mathrm{pH}$ 7.5). Each slide was stained with $50 \mu \mathrm{L}$ of $20 \mu \mathrm{g} / \mathrm{ml}$ ethidium bromides and covered with a cover slip. The photomicrograph of each slide was taken in Leica Fluorescent Microscope at the same magnification (40x).

Measurement of the comet head diameter, tail length, tail moment and percentage of DNA damages were followed the procedure as described by Helma and Uhl [27]. A total of 50 cells were screened per animal and examined in a fluorescence microscope (Leica 300-FX with 40x magnification). Quantification comet tail length (arbitrary unit) was as follows:

Comet tail length $=($ maximum total length $)-($ head diameter $)$.

Quantification of DNA damage for each cell was determined by Image J software as:

Total DNA in comet=(Total comet area) $\mathrm{x}$ (mean DNA intensity)

Total DNA in comet head=(Total head area) $\mathrm{x}$ (mean DNA intensity)

$\%$ DNA damage $=\frac{(\text { Total DNA in comet })-(\text { Total DNA in comet hea })}{(\text { Total DNA in comet })} \times 100$

Tail moment (arbitrary unit $)=(\%$ of DNA damage $) \mathrm{x}$ (tail length $)$.

\section{Molecular docking}

Docking experiments were performed by using docking interactive following software: Hex 5.1 (http://software.informer.com/getfreehex-5.1-software) and Chimera (http:// www.cgl. ucsf. edu/chimera/ download.html) to monitor the interactions between nicotine and DNA, nicotine and conjugated linolenic acid, nicotine and albumin, conjugated linolenic acid and DNA, and conjugated linolenic acid and albumin. Protein data bank (PDB) files of p53 consensus sequence (GGGCATGCCTAGGCATGCC) of human DNA (PDB ID: 3KMD), Human serum albumin (PDB ID:1R4I), nicotine and comjugated linolenic acid were fed in these soft wares for the experiments. Blast results indicated $73 \%$ homology between human serum albumin and Rattus norvegicus serum albumin protein sequences, thus human serum albumin was selected to monitor docking phenomena.

\section{Statistical analysis}

Whole experimental set up was repeated twice and data $(n=20)$ were averaged and given mean \pm S.D. The statistical analysis of the data obtained from control, nicotine and nicotine + conjugated linolenic acid supplemented groups was performed by one way analysis of variance (ANOVA) along with all pair wise Multiple Comparison Procedures (Holm-Sidak method) by using Sigma Stat (version 3.2). The significant levels of the observed data were determined at $\mathrm{P}<0.01$ (significant) and $\mathrm{P}<0.001$ (more or highly significant).

\section{Results}

Nicotine treatment caused significant $(\mathrm{P}<0.01)$ increase of total cholesterol, triglyceride (Figure 1) and VLDL-cholesterol (Figure $2)$. More significant $(\mathrm{P}<0.001)$ increase of $\mathrm{LDL}$-cholesterol and significant reduction of HDL-cholesterol in plasma were also noted in nicotine treated rats (Figure 2). Supplementation of conjugated linolenic acid significantly $(\mathrm{P}<0.01)$ antagonized nicotine-induced toxic effects (Figure 1,2). Concentration of lipid peroxidative product both in plasma (Figure 3) and liver (Figure 4) were increased more significantly by nicotine. It was noted that conjugated linolenic acid supplementation significantly ameliorated the nicotine-induced oxidative damage in rats and the effect was more prominent when used at lower concentration of CLnA (sunflower oil: conjugated linolenic acid: 99.5:0.5 w/w $)$ in the diet. More significantly $(\mathrm{P}<0.001)$ decreased activities of CAT (Figure 5), SOD (Figure 6) and GPx (Figure 7) were observed in liver of nicotine-treated rats as compared to control (untreated) rats. Dietary supplementation of conjugated linolenic acid showed increased activity of scavenging enzymes in liver (Figure 5-7). Reduced glutathione content in liver was also decreased due to nicotine treatment, which was attenuated by CLnA supplementation (Figure 8).

Figure 9 summarizes the observed values of total DNA contents of nicotine-induced liver tissue of rats. All these data were averaged over 20 animals. The total DNA contents in liver of rats were estimated as $1.82 \pm 0.07 \mathrm{mg} / \mathrm{g}$ tissues. Nicotine treatment decreased 37\% total DNA

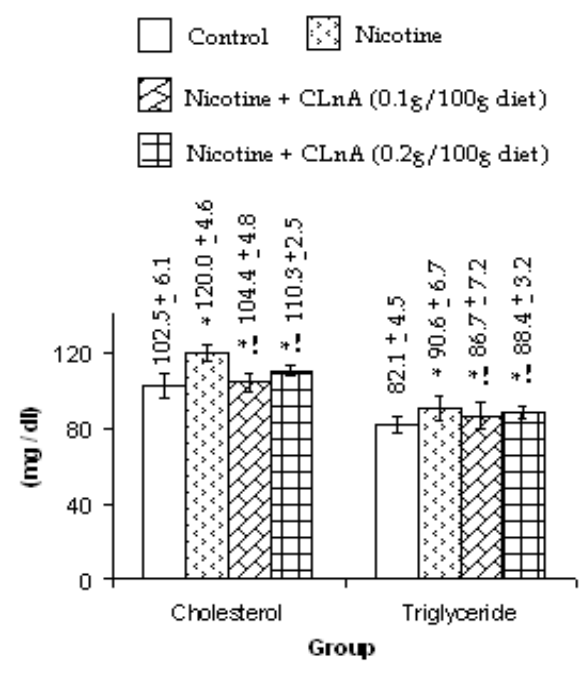

Figure 1: Plasma lipid profile.

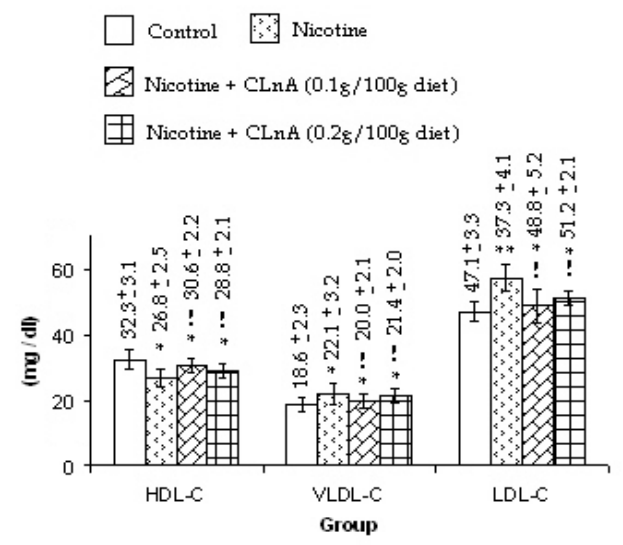

Figure 2: Plasma lipoprotein cholesterol. 
Citation: Chattopadhyay K, Maity M, Banerjee S, Chattopadhyay B (2012) Ameliorative Role of Dietary Supplemented Conjugated Linolenic Acid against Nicotine-Induced Toxicity in Rats. Pharmaceut Anal Acta 3:182. doi:10.4172/2153-2435.1000182

$$
\text { Control } \because \text { Nicotine }
$$

$B$ Nicotine + CLnA $(0.1 \xi / 100 g$ diet $)$

Nicotine + CLnA $(0.2 \xi / 100 g$ diet $)$

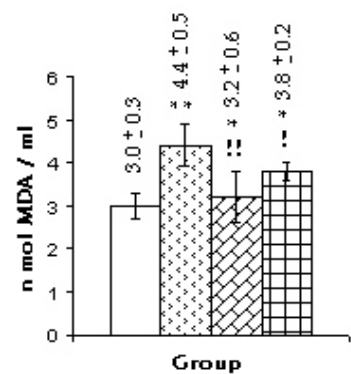

Figure 3: Plasma lipid peroxidation.

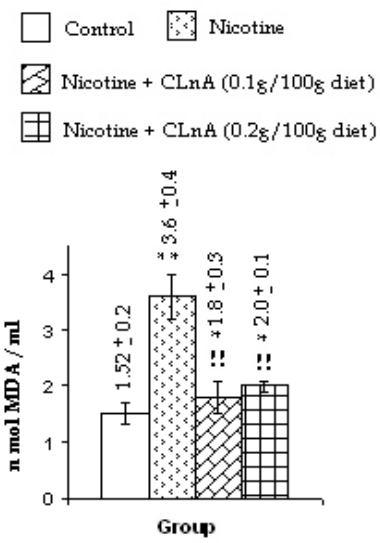

Figure 4: Liver lipid peroxidation.

contents in rats liver tissues compared to the control, which was very much significant $(\mathrm{P}<0.001)$ as seen from figure 9. Supplementation of conjugated linolenic acid $(0.1 \mathrm{~g}$ CLnA/ $100 \mathrm{~g}$ diet which is equivalent to sunflower oil: conjugated linolenic acid: $99.5: 0.5 \mathrm{w} / \mathrm{w})$ showed its antagonistic effect on nicotine-induced reduction of total DNA content of liver tissue because the total DNA content was decreased only $9 \%$ in that case compared to its control. This implied that the total DNA content was increased more significantly $(\mathrm{P}<0.001)$ due to conjugated linolenic acid supplementation compared to nicotine treatment. Photomicrographs of the Comet assay of rat liver tissue DNA are shown in figure 10. Comet like pictures of hepatic DNA appeared due to nicotine treatment were normalizes to some extent on CLnA supplementation. Figure 11 shows the extent of the rat liver tissue DNA damage and figure 12 shows the comet tail moment due to nicotine and nicotine with conjugated linolenic acid supplementation. Nicotine significantly increased the percentage of DNA damage (50.6\%) in liver tissues of rats compared to its control (7.2\%). In comparison with the DNA damage caused by nicotine, conjugated linolenic acid $(0.1 \mathrm{~g}$ CLnA / 100 g diet) reduced the values to $31.8 \%$. The increased value of tail moment (almost 24 times compared to control) by nicotine and the decreased value of tail moment (9.4 times for $0.1 \mathrm{~g}$ CLnA/100 g diet) by conjugated linolenic acid supplementation in nicotine-induced liver tissues were also confirmed the aggravated effect of nicotine on DNA damage and ameliorative effect of conjugated linolenic acid against nicotine treatment. Each data in this graph was the average of all observations from four animals in each group (for each animal 50 cells were screened).

DNA - nicotine docking indicated that nicotine could bind to the thymidine 6-consensus sequence of p53 gene (GGGCATGCCTAGGCATGCC) (PBD ID 3KMD) of human with a free energy change of $-163.74 \mathrm{kcal}$ (Figure 13). CLnA showed its capability to bind with DNA (Figure 14), though there was no direct interaction between nicotine and CLnA as revealed from docking experiment (Figure 15). Albumin - nicotine docking showed a free energy change of $-175.18 \mathrm{kcal}$ and 3 pseudo-bond formations between arginine 428 (chain $\mathrm{B}$ ) of albumin and $1 \mathrm{C}, 1 \mathrm{~N}$ and $1 \mathrm{H}$ of nicotine (Figure 16). Albumin -CLnA docking showed a free energy change of $-272.34 \mathrm{kcal}$ (Figure 17) with number of contacts were 3.

\section{Discussion}

Dietary intervention, particularly the use of traditional foods derived from natural sources, is the mainstay in the management of nicotine toxicity. In this context, there has been a growing interest in recent times in identifying as many dietary sources as possible for their ability to control the toxic effect of nicotine [28]. The present report indicates that there is a significant increase in plasma TC, triglyceride, LDL-C and VLDL-C and a significant decrease in plasma HDL-C of the nicotine-treated rats, which are in agreement with the earlier studies $[29,30]$.

The process of lipid peroxidation (LPO) plays an important role

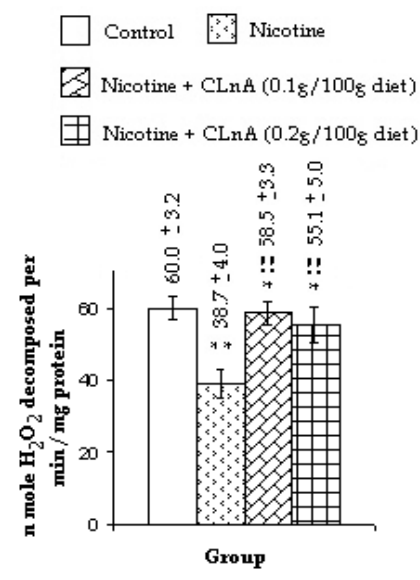

Figure 5: Liver catalase.

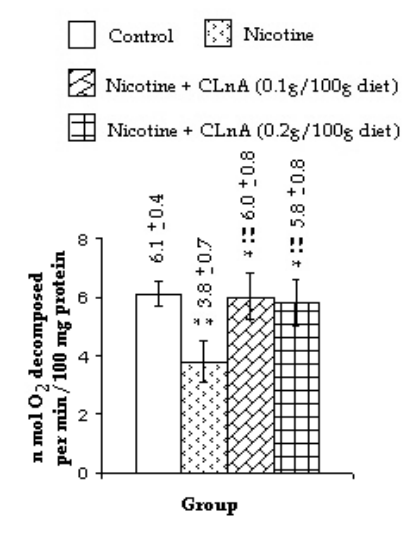

Figure 6: Liver superoxide dismutase. 

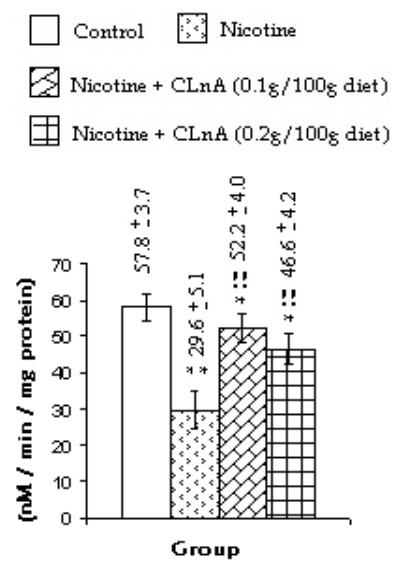

Figure 7: Glutathione peroxidase.
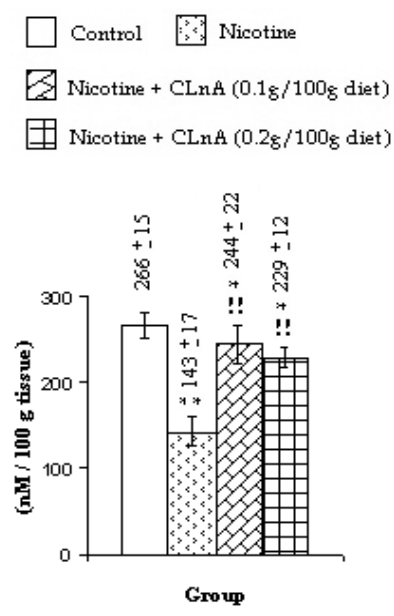

Figure 8: GSH in Liver.

in the pathogenesis of numerous human diseases. The membrane phospholipids breakdown and lipid peroxidation demonstrated in many diseases might be free radical mediated [31]. Lipid peroxidation leads to changes in membrane fluidity and permeability and also enhances rates of protein degradation. These will eventually lead to cell lysis [28]. In the present study, the levels of MDA, an end product of lipid peroxidation, is significantly increased in both plasma and liver. The initiation of LPO is carried out in most cases by free radicals such as superoxide, hydroxyl radicals etc. and other reactive oxygen species like $\mathrm{H}_{2} \mathrm{O}_{2}$. The increased concentration of LPO products observed in nicotine treated rats is also associated with decreased activity of scavenging enzymes such as catalase and superoxide dismutase. A decrease in the activities of these enzymes can lead to the excessive availability of superoxides and peroxides radicals, which in turn generate hydroxyl radicals resulting in the initiation and propagation of LPO.

Enzymatic antioxidants like SOD, CAT, and GPx constitute a mutually supportive team of defense against ROS that have been found to decrease in nicotine treated rats. SOD, the mitochondrial enzyme and usually found in plasma membrane, is a ubiquitous enzyme and protects aerobic cells against ROS [32]. The tetrameric hemoprotein CAT undergoes alternate divalent oxidation and reduction at its active site in the presence of $\mathrm{H}_{2} \mathrm{O}_{2}$ and catalyzes the dismutation reaction [33].
GPx is a seleno enzyme two-thirds of which is present in cytosol and one-third in mitochondria. It catalyzes the reaction of hydroperoxides with GSH to form glutathione disulfide (GSSG) and the reduced product of the hydroperoxide [34]. Depletion in the activities of SOD, CAT and GPx in the liver of nicotine-treated rats may be due to the increased utilization of these antioxidants to counter lipid peroxidation.

Glutathione is an important constituent of intracellular protective mechanisms against various noxious stimuli including oxidative stress. Glutathione reacts directly with ROS and electrophilic metabolites,
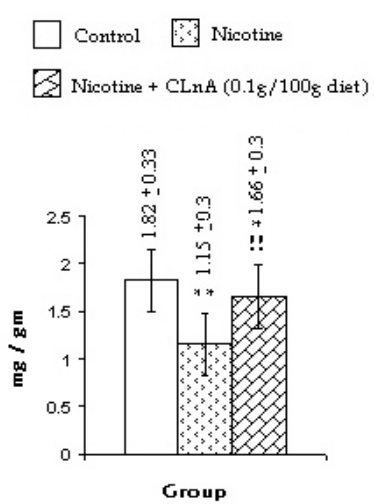

Figure 9: DNA content of Liver tissue.
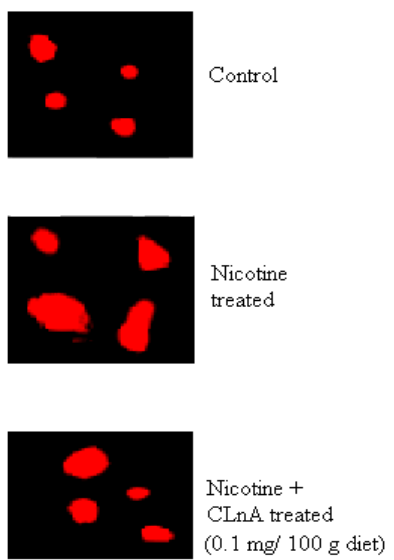

Figure 10: Photomicrographs of comet assay of liver tissue.

$$
\text { Control Nicotine }
$$

$B$ Nicotine + CLnA $(0.1 \mathrm{~g} / 100 \mathrm{~g}$ diet $)$

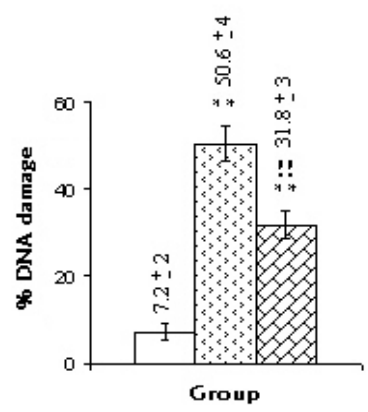

Figure 11: DNA damage. 
Citation: Chattopadhyay K, Maity M, Banerjee S, Chattopadhyay B (2012) Ameliorative Role of Dietary Supplemented Conjugated Linolenic Acid against Nicotine-Induced Toxicity in Rats. Pharmaceut Anal Acta 3:182. doi:10.4172/2153-2435.1000182

\section{Control Nicotine}

3 Nicotine + CLnA $(0.1 \mathrm{~g} / 100 \mathrm{~g}$ diet $)$

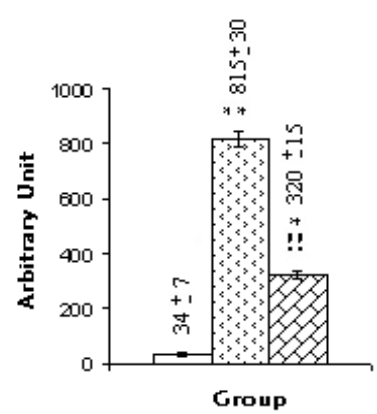

Figure 12: Comet tail length.

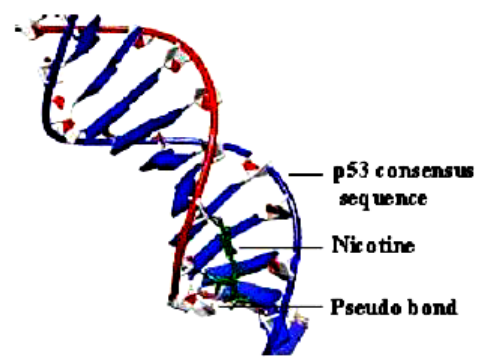

Free enegy change $-163.75 \mathrm{kcal}$

Figure 13: Nicotine - DNA docking.

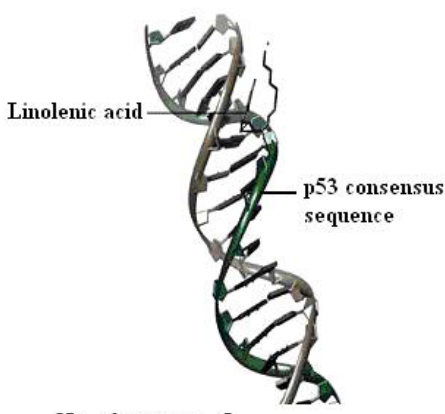

No. of contacts -5

(C13, H25 of LNL bonds with C5 of DNA;

$\mathrm{H} 20$ of LNL bonds with $\mathrm{O} 4$ of DNA; $\mathrm{H} 3$

of LNL bonds with of $\mathrm{C4}, \mathrm{O} 4$ of DNA)

Figure 14: CLnA - DNA docking.

protects essential thiol groups from oxidation, and serves as a substrate for several enzymes [35]. Thus, a decrease in GSH not only impairs cell defense against toxic compounds, but also results in enhanced oxidative stress and tissue damage. Reports indicate that, tissue injury induced by various stimuli is coupled with GSH depletion [36]. Hepatic GSH plays a crucial role in both scavenging ROS and detoxification of drugs [37]. It has been proposed that antioxidants, which maintain the concentration of reduced GSH, may restore the cellular defense mechanisms, block lipid peroxidation and thus protect against the oxidative tissue damage.

Supplementation of CLnA causes improvement in antioxidant status and reduction in lipid peroxidation. CLnA can possibly reduce generation of free radicals by scavenging the peroxyl radicals. Another possible explanation may be that the bio-hydrogenation or free radical addition to one of the conjugated double bonds of CLnA might have taken place, resulting in the formation of conjugated dienes that could have possibly acted as antioxidants as suggested by Ip et al. [38]. The possible mechanism concludes in the hydroperoxide formation and bio-hydrogenation of CLnA. Conjugated linolenic acid could act in several ways to reduce cholesterol level. Initially, uptake of cholesterol in the gastrointestinal tract could be inhibited and finally hydroxymethyl-glutaryl-CoA reductase (HMG CoA reductase), rate-limiting enzyme of cholesterol biosynthesis, could be inhibited.

Dhar et al. [15] have reported that CLnA present in karela seed oil has scavenging action against lipid peroxidation. It is observed that $0.5 \%$ a-eleostearic acid present in the diet (sunflower oil: conjugated linolenic acid: 99.5:0.5 w/w) is sufficient to show optimal scavenging activity. The amelioration study of CLnA against nicotine-induced genotoxicity is thus performed by supplementing $0.5 \%$ CLnA in the diet of the animals. Nicotine causes more significant $(\mathrm{P}<0.001)$ decrease in total DNA contents of the liver tissues compared to its control (Figure 9). Total DNA content of liver tissue for rats in control group is determined as $1.82 \mathrm{mg} / \mathrm{g}$ of liver tissues. The same for nicotineinduced liver tissues of rats is obtained as $1.15 \mathrm{mg} / \mathrm{g}$ tissues. The purity of the isolated DNA has been checked by the ratios of absorbance (A) of isolated DNA $\left(\mathrm{A}_{230} / \mathrm{A}_{260}=0.418\right.$ and $\left.\mathrm{A}_{260} / \mathrm{A}_{280}=1.798\right)$. This is very much comparable with previously published data $\left(\mathrm{A}_{230} / \mathrm{A}_{260}=0.40\right.$, $\left.\mathrm{A}_{260} / \mathrm{A}_{280}=1.82\right)[39,40]$. Excessive generation of ROS overwhelms the antioxidant defense system that can oxidize DNA and generate a large number of oxidative DNA modifications, including strand breaks and base oxidations [41]. Increased DNA breakdown results an increased rate of cell death [8], which may explain the decreased DNA content in nicotine treated liver tissues. Mohammed et al. [42] have observed similar finding in which the cellular proliferation and extra-cellular

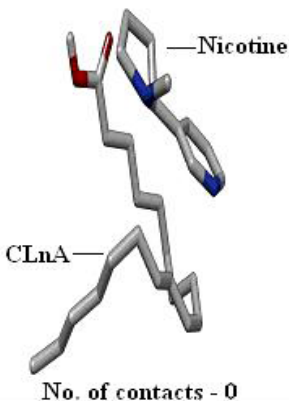

Figure 15: Nicotine - CLnA docking.

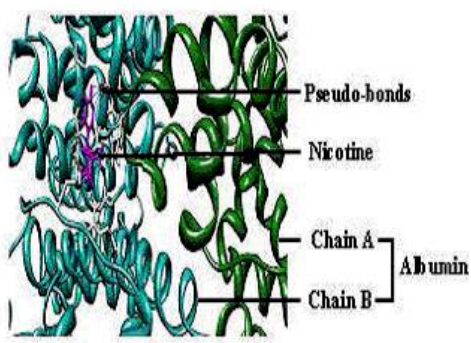

Free energy change $-175.18 \mathrm{kcal}$

Figure 16: Nicotine - albumin docking. 


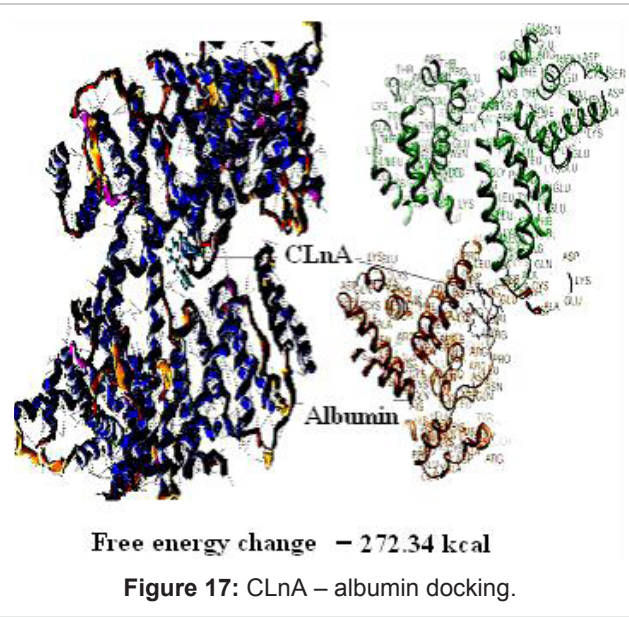

matrix synthesis of nucleus pulposus disc cells are severely affected by nicotine.

Owing to its high sensitivity, the Comet assay is considered as a good DNA damage detecting method [43]. The result of Comet assay (Figure 10-12) shows that there is only 7.2\% DNA damage occurred in the liver tissues of control rats (Figure 11), which is acceptable. But due to nicotine treatment the DNA damage more significantly $(\mathrm{P}<$ 0.001 ) increases to $50.6 \%$. As DNA damage is directly proportional to the tail moment, the large value of the tail moments (24 times compared to control) confirms the higher degree of DNA damage in nicotine-treated condition. This observation also supports the previous published results $[8,9,26]$. Nicotine causes in vivo DNA single-strand breaks (SSB) in lung and liver of mice [44] and increases the DNA fragmentation in mini organ cultures [45]. The comet like photographs (indicated as red colors in figure 10) of rat liver nuclear DNA treated with nicotine and stained with ethidium bromide is a clear indication of DNA stand breakage compare to the control liver cells. Due to the oxidative DNA damage by nicotine, the total DNA content in the liver tissues is decreased. This reduction is minimized by conjugated linolenic acid for which the total DNA content is seen to increase ( $1.66 \mathrm{mg} / \mathrm{g}$ tissue) in conjugated linolenic acid mediated liver tissues (Figure 9). The analytical results of the Comet assay (Figure 11,12) and photographs (Figure 10) of the nuclear DNA of liver cells (showing less migration as indicated colors of red in the pictures) confirm the protective effect of conjugated linolenic acid against nicotine-induced genotoxicity.

Wang et al. [46] and Banerjee et al. [9] have shown that nicotine is capable of binding with BSA to form complex and they explained the role of BSA in the detoxification and/or transportation of nicotine. The results of docking in this study shows that CLnA is also capable of binding with BSA (Figure 16) and the interaction between CLnA - BSA (free energy change $-272.34 \mathrm{kcal}$ ) (Figure 15) is more favourable than that of nicotine -BSA (free energy change $-175.18 \mathrm{kcal}$ ) as revealed from the free energy changes. Thus CLnA may protect the cellular components against damages caused by nicotine. Similarly nicotine and CLnA both are capable of binding with the consensus sequence of p53 gene (GGGCATGCCTAGGCATGCC) (PBD ID 3KMD) of human DNA. The results of these experiments show that conjugated linolenic acid reduces the effect of nicotine on DNA when supplemented to the diet which can be explained by the binding interaction with CLnA - DNA as seen from docking experiments. The exact mechanism of action of conjugated linolenic acid against nicotine-induced toxicity may be evaluated by the study of mRNA and protein expression profiles of inflammatory cytokines and signature signaling molecules of nicotine treated and nicotine along with conjugated linolenic acid supplemented tissues. This will certainly unfold the mystery of action of nicotine and its amelioration by conjugated linolenic acid in human system.

\section{Conclusions}

Nicotine adversely affects plasma lipid profile, promotes lipid peroxidation in plasma and liver tissues and reduces liver antioxidant enzymes activities in rats. It also causes severe DNA damage in liver tissues of rats also. Though Karalla is one of the very common and cheap vegetables found throughout the year, people do not like it much for its bitter taste. Conjugated linolenic acid present in Karalla seed seems to be a highly promising agent against chronic nicotine induced oxidative damages for its potential free radical scavenging and antioxidant properties. Thus conjugated linolenic acid supplemented diet may protect our body against nicotine-induced toxicity.

\section{Acknowledgement}

K. Chattopadhyay is gratefully acknowledged the financial support of Department of Science and Technology, Government of India, New Delhi for providing the research grant under WOS-A scheme (2008-2011). Experimental facilities provided by the Biophysics Laboratory of Jadavpur University, Physics Department and continuous inspiration of Late Dr. Shantinath Ghosh (Mentor of K. Chattopadhyay) are gratefully acknowledged.

\section{Conflict of Interest Statements}

The manuscript is totally free from any Conflict of Interest.

\section{References}

1. Mackay J, Eriksen M (2002) The Tobacco Atlas. World Health Organization, Geneva, Switzerland, pp 128.

2. Benowitz NL (2009) Pharmacology of nicotine: Addiction, smoking-induced disease and therapeutics. Annu Rev Pharmacol Toxicol 49: 57-71.

3. Neogy S, Das S, Mahapatra SK, Mandal N, Roy S (2008) Amelioratory effect of Andrographis paniculata Nees on liver, kidney, heart, lung and spleen during nicotine induced oxidative stress. Environ Toxicol Pharmacol 25: 321-328.

4. Mahapatra SK, Das S, Bhattacharjee S, Gautam N, Majumdar S, Roy S (2009) In vitro nicotine-induced oxidative stress in mice peritoneal macrophages: a dose dependent approach. Toxicol Mech Method 19: 100-108.

5. Ashakumary L, Vijayammal PL (1996) Additive effect of alcohol and nicotine on lipid peroxidation and antioxidant defence mechanism in rats. J Appl Toxicol 16: 305-308.

6. Hukkanen J, Jacob IIIP, Benowitz NL (2005) Metabolism and disposition kinetics of nicotine. Pharmacol Rev 57: 79-115.

7. Kleinsasser NH, Sassen AW, Semmler MP, Harreus UA, Licht AK, et al. (2005) The tobacco alkaloid nicotine demonstrates genotoxicity in human tonsillar tissue and lymphocytes. Toxicol Sci 86: 309-317.

8. Banerjee S, Chattopadhyay K, Chhabra JK, Chattopadhyay B (2012) Protein dependent fate of hepatic cells under nicotine induced stress and curcumin ameliorated condition. Eur J Pharmacol 684:132-145.

9. Banerjee S, Bandyopadhyaya G, Chattopadhyay K, Chattopadhyay BD (2010) Amelioration of nicotine-induced damage of blood cells in protein malnourished female rats by curcumin. Int J Pharmacol 6: 444-455.

10. Tsuzuki T, Tokuyama Y, Igarashi M, Miyazawa T (2004) Tumor growth suppression by a-eleostearic acid, a linolenic acid isomer with a conjugated triene system via lipid peroxidation. Carcinogenesis 25: 1417-1425

11. Koba K, Akahoshi A, Yamasaki M, Tanaka K, Yamada K (2002) Dietary Conjugated Linolenic Acid in relation to CLA differently modifies body fat mass and serum and liver lipid levels in rats. Lipids 37: 343-350.

12. Mukherjee C, Bhattacharyya S, Ghosh S, Bhattacharyya DK (2002) Dietary effects of punicic acid on the composition and peroxidation of rat plasma lipid. J Oleo Sci 51: 513-522. 
Citation: Chattopadhyay K, Maity M, Banerjee S, Chattopadhyay B (2012) Ameliorative Role of Dietary Supplemented Conjugated Linolenic Acid against Nicotine-Induced Toxicity in Rats. Pharmaceut Anal Acta 3:182. doi:10.4172/2153-2435.1000182

Page 8 of 8

13. Chakroborty SP, Mahapatra SK, Sahu SK, Pramanik P, Roy S (2011) Antioxidative effect of folate- modified chitosan nanoparticles. Asian Pac J Trop Biomed 1: 29-38.

14. Bhattacharyya AC, Majumdar S, Bhattacharyya DK (1986) Edible quality rice bran oil from high FFA rice bran oil by miscella refining. J Am Oil Chem Soc 63: 1189-1191.

15. Dhar P, Ghosh S, Bhattacharyya DK (1999) Dietary effects of conjugated octadecatrienoic fatty acid (9 cis, 11 trans, 13 trans) levels on blood lipids and nonenzymatic in vitro lipid peroxidation in rats. Lipids 34: 109-114.

16. Allain CC, Poon LS, Chan CS, Richmond WS, Fu PC (1974) Enzymatic determination of total serum cholesterol. Clin Chem 20: 470- 475.

17. Warnick GR, Nguyen T, Albers AA (1985) Comparison of improved precipitation methods for quantification of high-density lipoprotein cholesterol. Clin Chem 31: 217-222.

18. Werner M, Gabrielson DG, Estman J (1981) Ultramicro determination of serum triglycerides by bioluminescent assay. Clin Chem 27: 268-271.

19. Friedewald WT, Levy RI, Fredrickson DS (1972) Estimation of the concentration of low-density lipoprotein cholesterol in plasma, without use of the preparative ultracentrifuge. Clin Chem 18: 499-502.

20. Chatterjee SN, Agarwal S (1998) Liposomes as membrane model for study of lipid peroxidation. Free Radic Biol Med 4: 51-72.

21. Beauchamp C, Fridovich I (1971) Superoxide dismutase: improved assays and an assay applicable to acrylamide gels. Anal Biochem 44: 276-287.

22. Cohen G, Dembiec D, Marcus J (1970) Measurement of catalase activity in tissue extracts. Anal Biochem 34: 30-38.

23. Paglia DE, Valentine WN (1967) Studies on the quantitative and qualitative characterization of erythrocyte glutathione peroxidase. J Lab Clin Med 70:158169

24. Griffith OW (1980) Determination of glutathione and glutathione sulfide using glutathione reductase and 2-vinyl pyridine. Anal Biochem 106: 207-212.

25. Lowry OH, Rosebrough NJ, Farr AL, Randall RJ (1951) Protein measurement with the folin phenol reagent. J Biol Chem 193: 265-275.

26. Bandyopadhyaya G, Sinha S, Chattopadhyay BD, Chakraborty A (2008) Protective role of curcumin against nicotine-induced genotoxicity on rat liver under restricted dietary protein. Eur J Pharmacol 588: 151-157.

27. Helma C, Uhl M (2000) A public domain image-analysis program for the singlecell gel-electrophoresis (Comet) assay. Nutr Res 466: 9-15.

28. Sener G, Sehirli AO, Ipci Y, Cetinel S, Cikler E, Gedik N (2005) Chronic nicotine toxicity is prevented by aqueous garlic extract. Plant Foods Hum Nutr 60: 77 86.

29. Chattopadhyay K, Mandal S, Chattopadhyay BD, Ghosh S (2010) Ameliorative effect of sesame lignans on nicotine toxicity in rats. Food Chem Toxicol 48: 3215-3220.

30. Sinha S, Maiti M, Chattopadhyay K, Chattopadhyay BD (2012) Potential amelioration of curcumin against nicotine-induced toxicity of protein malnourished female rats. J Pharmacol Toxicol 4: 166-180.

31. Kalpana C, Rajasekharan KN, Menon VP (2005) Modulatory effects of curcumin and curcumin analog on circulatory lipid profiles during nicotineinduced toxicity in wistar rats. J Med Food 8: 246-250.

32. Powers SK, Kavazis AN, McClung JM (2007) Oxidative stress and disuse muscle atrophy. J Appl Physiol 102: 2389-2397.

33. Balakrishnan A, Menon VP (2007) Antioxidant properties of hesperidin in nicotine-induced lung toxicity. Fund Clin Pharmacol 21: 535-544.

34. Ayene IS, Biaglow JE, Kachur AV, Stamato TD, Koch CJ (2008) Mutation in G6PD gene leads to loss of cellular control of protein glutathionylation: Mechanism and implication. J Cell Biochem 103: 123-135.

35. Sener G, Toklu HZ, Cetinel S (2007) $\beta$-Glucan protects against chronic nicotineinduced oxidative damage in rat kidney and bladder. Env Toxicol Pharmacol 23: 25-32.

36. Sreekala S, Indira M (2009) Effects of exogenous selenium on nicotine-induced oxidative stress in rats. Biol Trace Elem Res 130: 62-71.

37. Husain K, Scott BR, Reddy SK, Somani SM (2001) Chronic ethanol and nicotine interaction on rat tissue antioxidant defense system. Alcohol 25: 89-97.

38. Ip C, Scimeca JA, Thompson HJ (1994) Conjugated linoleic acid: A powerfu anticarcinogen from animal fat sources. Cancer 74: 1050-1054.

39. Marmur $\mathrm{J}$ (1961) A procedure for the isolation of deoxyribonucleic acid from microorganism. J Mol Biol 3: 208-218.

40. Muller R, Rajewsky MF (1980) Immunological quantification by high-affinity antibodies of O6-ethyldeoxyguanosine in DNA exposed to N-ethyl-Nnitrosourea. Cancer Res 40: 887-896.

41. Bhattacharya K, Alink G, Dopp E (2007) Oxidative stress and changed gene expression profiles in fibre-/particle-induced carcinogenesis. Int J Hum Genet 7: 1-21.

42. Mohammed A, Kesani A, Anand B, Singh A, Wiseman M, et al. (2004) Effect of nicotine on spinal disc cells: a cellular mechanism for disc degeneration. Spine 29: $568-575$.

43. Lee RF, Steinert S (2003) Use of the single cell gel electrophoresis /Comet assay for detecting DNA damage in aquatic (marine and freshwater) animals. Mutat Res 544: 43-64.

44. Villard PH, Seree EM, Re JL, De Meo M, Barra Y (1998) Effects of tobacco smoke on the gene expression of the Cyp1a, Cyp2b, Сyp2e and Сyp3a subfamilies in mouse liver and lung: relation to single-strand breaks of DNA Toxicol Applied Pharmacol 148: 195-204.

45. Sassen AW, Richter E, Semmler MP, Harreus UA, Gamarra F, et al (2005) Genotoxicity of nicotine in mini-organ cultures of human upper aerodigestive tract epithelia. Toxicol Sci 88: 134-141.

46. Wang Y, Cheng Y, Sun HF (2000) Interaction of nicotine and bovine serum albumin. Chinese Chem Lett 11: 247-250. 